\title{
Application of Bap-65: A New Score for Risk Stratification in Acute Exacerbation of Chronic Obstructive Pulmonary Disease
}

\author{
Rabih Tabet*, Charbel Ardo, Paul Makhlouf and Jeff Hosry
}

Department of Cardiovascular Medicine, Faculty of Medical Sciences, The Lebanese University, Hadath, Beirut, Lebanon

\begin{abstract}
Background and objectives: COPD is gaining importance in the field of public health because it is expected to become the third leading cause of death worldwide by 2020 . Until today, there is no validated score for risk stratification of patients presenting with an exacerbation of COPD to the emergency department. The BAP-65 is a new score, published in 2011 in the "CHEST» journal, which was used to predict the need for mechanical ventilation and predict the risk of mortality in acute exacerbation of COPD. Thus, we decided to conduct this study and apply the BAP-65 score in Lebanon, in order to test its accuracy in correlating the clinical and biological status of the patient presenting with acute exacerbation of COPD with mortality risk and the possible use of MV.
\end{abstract}

Methods: We analysed 980 admissions to two Lebanese hospitals (2005 through 2013) with a discharge diagnosis of acute exacerbation of COPD. The primary endpoints were hospital mortality and need for MV. We used the SPSS program - Version 17 in our analysis.

Results:170 patients (17.3\%) required mechanical ventilation and 59 patients $(6 \%)$ passed away during hospitalization. Statistics showed that both end points increased with increasing BAP-65. $1.3 \%$ of patients with a score of 0 or 1 needed intubation, while $74 \%$ of patients with a score of 3 or 4 were intubated (P-value $<0.001)$. Moreover, $<1 \%$ of patients with a score of 0 or 1 passed away, while $51 \%$ of patients with a score of 3 or 4 died (P-value $<0.001)$.

Conclusions: The BAP-65 scoring system seems to be a useful and simple tool to classify the patients presenting with AECOPD, and it correlates with both need for mechanical ventilation and mortality. Most importantly, it showed consistent results when applied in different populations.

Keywords: BAP-65 scoring system - Blood urea nitrogen - Mental status - Pulse - Age - Risk stratification - Acute exacerbation of COPD

List of abbreviations : COPD: Chronic obstructive pulmonary disease; MV: Mechanical ventilation; AECOPD: Acute exacerbation of chronic obstructive pulmonary disease; ICU: Intensive care unit; BUN: Blood urea nitrogen; GCS: Glasgow coma scale; ER: Emergency room

\section{Introduction}

Chronic obstructive pulmonary disease (COPD) is defined as a common preventable and treatable disease, characterized by persistent airflow limitation that is usually progressive and associated with an enhanced chronic inflammatory response in the airways and the lung to noxious particles or gases. Exacerbations and comorbidities contribute to the overall severity in individual patients [1].

Nowadays, COPD is the $4^{\text {th }}$ cause of mortality in the USA [2], and the $6^{\text {th }}$ in the world, it is also the $2^{\text {nd }}$ most common pulmonary cause of hospital admissions secondary to pneumonia. This disease is gaining importance in the field of public health, because it is expected to become the $3^{\text {rd }}$ cause of mortality worldwide in 2020 [3]. Acute exacerbation of COPD (AECOPD) can be mild, moderate or severe, thus, physicians should assess the severity of the exacerbation in order to decide how to manage the patient. Some can be treated safely as outpatients, others may need intubation and admission in ICU settings. Unfortunately, we still lack a precise stratification-risk score to help clinicians in assessing the severity of the exacerbation and predicting its prognosis [2]. The foundation of such a score would help in the triage of the patients, and classify them into low risk or high risk, and might guide further therapies and decision-makings. Several scores have been tested for this purpose, the most important were: The COPD and asthma physiology score (CAPS) [4], and DECAF score [5], but none of them is yet widely accepted or recommended to be used in practice [6]

In our study, we chose to test the BAP-65 score (Elevated BUN [> $25 \mathrm{mg} / \mathrm{dL}$ ], Altered mental status [GCS $\leq 14$ ], Pulse [>109], and Age [>65]), a new model that was developed to predict mortality and need for MV during hospitalization of patients with AECOPD, because it is a simple and rapid score, that is designed to only use variables that are generally available to physicians at the time of presentation (i.e: In the emergency department). This score was published in the CHEST journal in 2011, and it showed the ability to predict both the need for $\mathrm{MV}$ and the risk of mortality [2]. So we decided to put it in practice in some Lebanese hospitals and check its accuracy in correlating the biological and clinical picture of the patients with their outcome.

\section{Methods}

\section{Data source and cases}

We gathered our data from 2 Lebanese hospitals (Beirut Governmental University Hospital - BGUH and Hopital Notre Dame du Liban - HNDL) for the period from 2005 through 2013 after

*Corresponding author: Rabih Tabet, MD, Department of Cardiovascular Medicine, Faculty of Medical Sciences, The Lebanese University, Hadath, Beirut, Lebanon, Tel: +961-3-461562; E-mail: drabih tabet@hotmail.com

Received March 15, 2016; Accepted March 18, 2016; Published March 21, 2016

Citation: Tabet R, Ardo C, Makhlouf P, Hosry V (2016) Application of Bap-65 A New Score for Risk Stratification in Acute Exacerbation of Chronic Obstructive Pulmonary Disease. J Clin Respir Dis Care 2: 110. doi: 10.4172/ jcrdc. 1000110

Copyright: (C) 2016 Tabet $\mathrm{R}$, et al. This is an open-access article distributed under the terms of the Creative Commons Attribution License, which permits unrestricted use, distribution, and reproduction in any medium, provided the original author and source are credited. 
gaining approval from the Institutional Review Board (IRB) and the ethics committees at the Lebanese University, BGUH, and HNDL. We recorded all acute care admissions with a discharge diagnosis of AECOPD. Specifically, the database contained information concerning patient demographics, discharge diagnoses, need for MV, and hospital mortality. It also included patient vital signs, and results from laboratory testing. All people above 40 years of age were included (in order to minimize potential patients with asthma) in the analysis with an ICD10 discharge code of COPD with acute exacerbation (J44.0, J44.1 and J44.8). No funding was received for this study.

\section{BAP-65 classes and primary endpoints}

The BAP-65 system is a score composed of 4 variables; all of them are available upon presentation to the hospital. The B letter stands for Blood Urea Nitrogen (BUN) and it is positive if level is above $25 \mathrm{mg} / \mathrm{dL}$; The A letter stands for Altered Mental Status and it is counted positive when the initial GCS is 14 or less, or when the physician has designated that the patient was disoriented, stuporous or in coma; The P letter stands for Pulse and it is positive when the initial pulse is above 109 beats/min; and finally, an additional point will be added if the patient was above 65 of age. A BAP- 65 score was calculated for each patientcase in the study according to the criteria mentioned above. In-hospital mortality and need for MV at any point during the hospitalization served as co-primary end points.

\section{Statistical analysis}

After the data gathering, we used the Chi-squared test (Pearson) to compare between the categorical variables, and to assess the predictive ability of the BAP-65 for the primary endpoints (need for MV and mortality). A P value of $<0.05$ was considered statistically significant, and the tests were two-sided. One way/ANOVA test and analysis of variance were used for continuous variables. T-test and analysis of variance were used to study the relation between each continuous variable (age, BUN, pulse) and the primary endpoints. Chi-squared test (Pearson) was used for the categorical variable (level of consciousness).

\section{Results}

Patients baseline characteristics by BAP-65 class - After excluding all patients with potential asthma, the final population included 980 subjects with a principal diagnosis of AECOPD. As shown in Table 1 below, the mean age was 68 years with a standard deviation of 9.5 , and $67.6 \%$ of the patient-cases were men. The most common comorbidities were hypertension (43.9\%), diabetes mellitus (26.1\%), coronary artery disease (23.1\%), and congestive heart failure (16.4\%). $6 \%$ of patients passed away during their hospitalization, and $17.3 \%$ of them required intubation and $\mathrm{MV}$ at any point.

BAP-65 and primary endpoints - Mortality rate increased with increasing BAP class, based on Chi-squared test, with a $\mathrm{P}$ value of $<$ 0.0001 . It is shown in Figure 1 that mortality is $<1 \%$ in patients with BAP- 65 score of zero, while it jumps to $>50 \%$ in patients with BAP-65 score of 4 .

The need for MV (Figure 2) increased as well, as the score increased. Less than $1 \%$ of the patients with BAP- 65 score of zero needed MV at any time during hospitalization, while $>50 \%$ of patients with score of 4 were intubated and mechanically ventilated (based on Chi-Squared test, with a $P$ value of $<0.0001$ ).

Effect of each variable alone and the primary endpoints - Table 2 shows that each component of the BAP-65 score had an independent and significant correlation with both endpoints (MV need and mortality), except for the age, that correlated poorly with the need for MV.

\section{Discussion}

The analysis of the data gathered in this study demonstrates that the BAP-65 class correlates well with both in-hospital mortality and need for $\mathrm{MV}$, and it showed consistent results between two completely different populations (American and Lebanese). However, there are some weak points in our approach. First, we relied on administrative data for the diagnosis of AECOPD. This can be an inaccurate means for identifying patients cases; though this method have been used in almost all the studies worldwide, but anyway, we restricted the population to persons older than 40 years, minimizing the confounding risk between COPD and asthma. Similarly, we used a retrospective approach in our study, so a prospective one for validation of BAP-65 is certainly needed [7].

Additionally, we lacked information on the severity of chronic COPD of each patient, for example pulmonary function tests, and the revised GOLD classification. We expressly searched for a model that only requires simple information that was consistently available in ER departments, upon the presentation of the patient (Pulmonary function tests, for instance, are not always available to the physician in the ER) [7].

Given those results, despite that BAP-65 is unable to give an absolute number or quantify the risk of morbidity/mortality of patients with AECOPD, it provides the information, on the other hand, in a graded fashion. After having calculated the BAP-65 score, the patients can be classified into 3 categories: patients with a BAP- 65 score of 0 or 1 are in the low-risk category for intubation and/or mortality; patients with a score of 2 are at intermediate-risk; whereas patients with BAP65 score of 3 or 4 are in the high-risk category for intubation and/or mortality. This highlights its potential usefulness.

Our study constitutes a solid ground that adds to the initial work done in the USA previously, in developing the BAP- 65 model because we expressly applied the BAP-65 severity tool in a large group of patients (980 Lebanese patients) distinct from the population where it was initially developed. For any risk-scoring system to prove useful, it is crucial to document that the rubric remains accurate in a population separate from the one in which it was generated.

Why did BUN, mental status, and pulse correlate with mortality and MV need in persons with AECOPD? [7]. First, BUN has always correlated with bad prognosis in respiratory diseases. Specifically in AECOPD, it reflects intravascular volume depletion (due to decreased PO intake and hyperventilation in the hours or days prior to admission) [7]. Second, tachycardia has several significances: it reflects the volume status of the patient, and the degree of hypoxemia, also it may correlate with the general distress of the patient [7]. Finally, a decrease in mental status is a better predictor of the underlying pathophysiologic mechanisms of hypercapnia in AECOPD than direct measurement of the partial pressure of carbon dioxide, because some patients with chronic respiratory failure tolerate high levels of $\mathrm{PaCO}_{2}$ well, without showing any clinical disturbance [7].

Why BAP-65 score appears to be better suited for clinical use than CAP score or DECAF score? First of all, the BAP-65 is the simplest model among the rest and the quickest to be calculated. The others are somewhat more cumbersome. We only need the history and physical exam with the BUN level to calculate the BAP, but we need more laboratory tests and imaging in order to calculate the other scores (CBCD, electrolytes, creatinine, urea, albumin, ABGs, ECG, CXR...). This also raises the issue of cost/effectiveness and time-consumption, since these tests are costly and need time to be completed. 
Citation: Tabet R, Ardo C, Makhlouf P, Hosry V (2016) Application of Bap-65: A New Score for Risk Stratification in Acute Exacerbation of Chronic Obstructive Pulmonary Disease. J Clin Respir Dis Care 2: 110. doi: 10.4172/ jcrdc.1000110

Page 3 of 4

\begin{tabular}{|c|c|c|c|c|c|c|}
\hline Variable & Overall Prevalence & BAP-65 score of 0 & BAP-65 score of 1 & BAP-65 score of 2 & BAP-65 score of 3 & BAP-65 score of 4 \\
\hline Total No. & 980 & $223(22.7 \%)$ & $357(36.4 \%)$ & $250(25.5 \%)$ & $125(12.8 \%)$ & $\begin{array}{c}25 \\
(2.6 \%)\end{array}$ \\
\hline Need for MV & $\begin{array}{c}170 \\
(17.3 \%)\end{array}$ & $\begin{array}{c}0 \\
(0 \%)\end{array}$ & $\begin{array}{c}8 \\
(2.2 \%)\end{array}$ & $51(20.4 \%)$ & $87(69.6 \%)$ & $\begin{array}{c}24 \\
(96 \%)\end{array}$ \\
\hline Mortality & $\begin{array}{c}59 \\
(6 \%)\end{array}$ & $\begin{array}{c}0 \\
(0 \%)\end{array}$ & $\begin{array}{c}0 \\
(0 \%)\end{array}$ & $\begin{array}{c}12 \\
(4.8 \%)\end{array}$ & $29(23.2 \%)$ & $\begin{array}{c}18 \\
(72 \%)\end{array}$ \\
\hline \multicolumn{7}{|l|}{ Demographics } \\
\hline Age (mean, standard deviation) & $\begin{array}{c}68 \\
(9.5)\end{array}$ & $\begin{array}{l}57.9 \\
(5.6)\end{array}$ & $\begin{array}{l}69.9 \\
(8.6)\end{array}$ & $\begin{array}{l}71.8 \\
(7.6)\end{array}$ & $\begin{array}{l}70.5 \\
(8.4)\end{array}$ & $\begin{array}{l}74.4 \\
(7.1)\end{array}$ \\
\hline Male & $\begin{array}{c}663 \\
(67.6 \%)\end{array}$ & $121(54.2 \%)$ & $252(70.5 \%)$ & $184(73.6 \%)$ & $89(71.2 \%)$ & $\begin{array}{c}17 \\
(68 \%)\end{array}$ \\
\hline Female & $\begin{array}{c}317 \\
(32.4 \%)\end{array}$ & $102(45.8 \%)$ & $105(29.5 \%)$ & $66(26.4 \%)$ & $36(28.8 \%)$ & $\begin{array}{c}8 \\
(32 \%)\end{array}$ \\
\hline \multicolumn{7}{|c|}{ Vital signs and level of consciousness } \\
\hline Pulse (mean, standard deviation) & $93.71(17.59)$ & $\begin{array}{l}84.6 \\
(9.6)\end{array}$ & $89.2(14.4)$ & $98.2(19.4)$ & $108.1(16.7)$ & $121.1(11.7)$ \\
\hline BUN (mean, standard deviation) & $25.02(12.51)$ & $\begin{array}{c}17 \\
(4.3)\end{array}$ & $\begin{array}{c}21 \\
(8.3)\end{array}$ & $31.1(13.5)$ & $35.8(11.4)$ & $37.8(11.4)$ \\
\hline Altered level of consciousness & $\begin{array}{c}126 \\
(12.8 \%)\end{array}$ & $\begin{array}{c}0 \\
(0 \%)\end{array}$ & $\begin{array}{c}4 \\
(1.1 \%)\end{array}$ & $\begin{array}{c}30 \\
(12 \%)\end{array}$ & $67(53.6 \%)$ & $\begin{array}{c}25 \\
(100 \%)\end{array}$ \\
\hline \multicolumn{7}{|l|}{ Comorbidity } \\
\hline Hypertension & $\begin{array}{c}431 \\
(43.9 \%)\end{array}$ & $74(33.1 \%)$ & $152(42.5 \%)$ & $128(51.2 \%)$ & $63(50.4 \%)$ & $\begin{array}{c}14 \\
(56 \%)\end{array}$ \\
\hline Coronary artery disease & $\begin{array}{c}227 \\
(23.1 \%)\end{array}$ & $27(12.1 \%)$ & $\begin{array}{c}86 \\
(24 \%)\end{array}$ & $\begin{array}{c}75 \\
(30 \%)\end{array}$ & $32(25.6 \%)$ & $\begin{array}{c}7 \\
(28 \%)\end{array}$ \\
\hline Diabetes mellitus & $\begin{array}{c}256 \\
(26.1 \%)\end{array}$ & $50(22.4 \%)$ & $91(25.4 \%)$ & $69(27.6 \%)$ & $38(30.4 \%)$ & $\begin{array}{c}8 \\
(32 \%)\end{array}$ \\
\hline Dyslipidemia & $\begin{array}{c}73 \\
(7.4 \%)\end{array}$ & $\begin{array}{c}29 \\
(13 \%)\end{array}$ & $\begin{array}{c}20 \\
(5.6 \%)\end{array}$ & $\begin{array}{c}16 \\
(6.4 \%)\end{array}$ & $\begin{array}{c}7 \\
(5.6 \%)\end{array}$ & $\begin{array}{c}1 \\
(4 \%)\end{array}$ \\
\hline Congestive heart failure & $\begin{array}{c}161 \\
(16.4 \%)\end{array}$ & $17(10.6 \%)$ & $56(15.6 \%)$ & $53(21.2 \%)$ & $31(24.8 \%)$ & $\begin{array}{c}4 \\
(16 \%)\end{array}$ \\
\hline Chronic kidney disease & $\begin{array}{c}20 \\
(2 \%)\end{array}$ & $\begin{array}{c}0 \\
(0 \%)\end{array}$ & $\begin{array}{c}4 \\
(1.1 \%)\end{array}$ & $\begin{array}{c}13 \\
(5.2 \%)\end{array}$ & $\begin{array}{c}2 \\
(1.6 \%)\end{array}$ & $\begin{array}{c}1 \\
(4 \%)\end{array}$ \\
\hline Atrial fibrillation & $\begin{array}{c}23 \\
(2.3 \%)\end{array}$ & $\begin{array}{c}3 \\
(1.3 \%)\end{array}$ & $\begin{array}{c}12 \\
(3.3 \%)\end{array}$ & $\begin{array}{c}5 \\
(2 \%)\end{array}$ & $\begin{array}{c}3 \\
(2.4 \%)\end{array}$ & $\begin{array}{c}0 \\
(0 \%)\end{array}$ \\
\hline Stroke & $\begin{array}{c}16 \\
(1.6 \%)\end{array}$ & $\begin{array}{c}5 \\
(2.2 \%)\end{array}$ & $\begin{array}{c}4 \\
(1.1 \%)\end{array}$ & $\begin{array}{c}1 \\
(0.4 \%)\end{array}$ & $\begin{array}{c}5 \\
(4 \%)\end{array}$ & $\begin{array}{c}1 \\
(4 \%)\end{array}$ \\
\hline Lung Cancer & $\begin{array}{c}10 \\
(1 \%)\end{array}$ & $\begin{array}{c}4 \\
(1.7 \%)\end{array}$ & $\begin{array}{c}3 \\
(0.8 \%)\end{array}$ & $\begin{array}{c}3 \\
(1.2 \%)\end{array}$ & $\begin{array}{c}0 \\
(0 \%)\end{array}$ & $\begin{array}{c}0 \\
(0 \%)\end{array}$ \\
\hline
\end{tabular}

Table 1: Patient baseline characteristics by BAP-65 Class.

Mortality

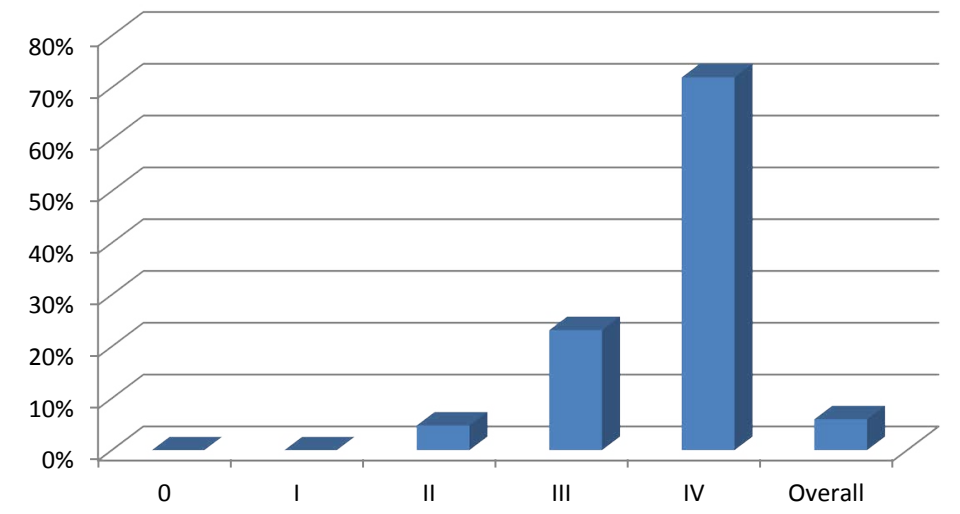

Horizontal - BAP-65 classes; Vertical - Percentage of mortality

Figure 1: Mortality by BAP-65 class. 


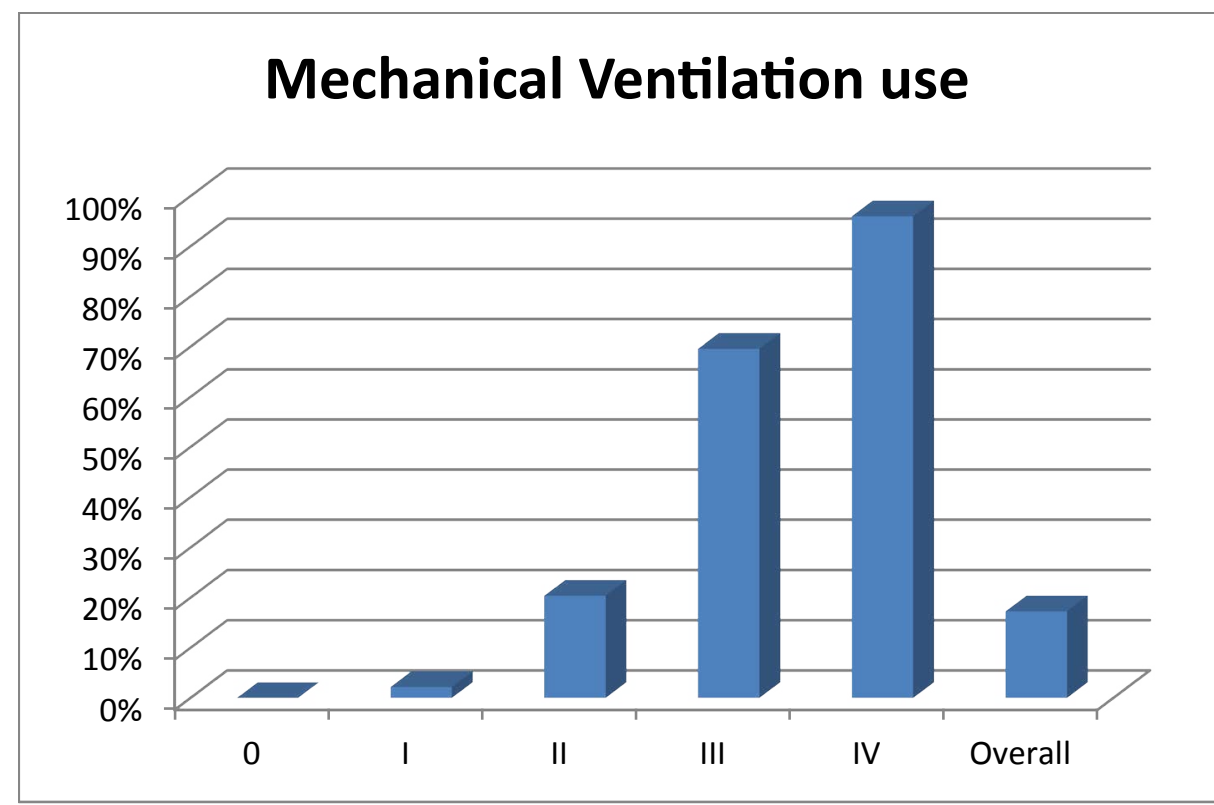

Horizontal - BAP-65 classes; Vertical - Percentage of mechanical ventilation need

Figure 2: Need for mechanical ventilation by BAP-65 class.

\begin{tabular}{|c|c|c|}
\hline \multicolumn{2}{|c|}{$\begin{array}{c}\text { Correlation between each variable of BAP-65 alone and the primary } \\
\text { endpoints }\end{array}$} \\
\hline Variable & $\begin{array}{c}\text { Correlation with } \\
\text { Mortality (P-value) }\end{array}$ & $\begin{array}{c}\text { Correlation with MV } \\
\text { (P-value) }\end{array}$ \\
\hline Age $^{*}$ & 0.0315 & 0.057 \\
\hline BUN $^{*}$ & 0.0005 & 0.0005 \\
\hline Pulse $^{*}$ & 0.0005 & 0.0005 \\
\hline Level of consciousness & 0.0005 & 0.0005 \\
\hline${ }^{*} P$-values of continuous variables were calculated by T-test \\
\hline${ }^{*}$ P-values of categorical variables were calculated by Chi-Squared test \\
\hline
\end{tabular}

Table 2: Effect of each variable of BAP-65 alone on mortality and MV need.

Moreover, none of these scores predicts the risk of endotracheal intubation and mechanical ventilation need. They only correlate with mortality rate. The BAP- 65 was found to correlate with both mortality and mechanical ventilation.

Furthermore, most variables of the BAP-65 are objective. So it can be applied with consistency and generalizability. This is an essential characteristic of any excellent clinical score [2].

\section{Conclusion}

As a summary, we can tell that the BAP-65 scoring system seems to be a promising model in our medical practice. It showed to be both a simple and accurate tool in classifying the patients presenting with AECOPD into low, intermediate, and high-risk, and it correlated with both need for MV and mortality. Also it seems to be a generalizable score, applicable in all different populations where it was tested.

In the end, remember that no clinical decision rule is infallible. BAP-65 should not replace the clinical sense of the physician. It is here to facilitate risk stratification of the patients presenting with AECOPD, and help clinicians in their triage, and complement their decision making.

\section{References}

\section{Acknowledgement}

The authors would like to thank Mrs Dayane Daccache who did the statistical analysis of this study.

\section{Declaration of Interest}

The authors have nothing to disclose, none of them has any conflict of interest. No financial support was given for this study.

\section{References}

1. Vestbo J, Hurd SS, Agustí AG, Jones PW, Vogelmeier C, et al. (2013) Global strategy for the diagnosis, management, and prevention of chronic obstructive pulmonary disease: GOLD executive summary. Am J Respir Crit Care Med 187: 347-365.

2. Shorr A, Sun X, Johannes R, Yaitanes A, Tabak YP (2011) Validation of a Novel Risk Score for Severity of Illness in Acute Exacerbations of COPD. Chest 140 1177-1183.

3. Reilly J, Silverman E, Shapiro S (2011) Chronic Obstructive Pulmonary Disease. In: Longo DL, Fauci AS, Kasper DL, et al. (eds.) Harrison's Principles of Internal Medicine (18 ${ }^{\text {th }}$ edn.) New York: McGraw-Hill pp: 2151-2160.

4. Wildman M, Harrison D, Welch C, Sanderson C (2007) A new measure of acute physiological derangement for patients with exacerbations of obstructive airways disease: The COPD and Asthma Physiology Score. Respir Med 101: 1994-2002.

5. Steer J, Gibson J, Bourke SC (2012) The DECAF Score: predicting hospital mortality in exacerbations of chronic obstructive pulmonary disease. Thorax 67: 970-976.

6. Chandra S, Keri K, Jariwala U, Marur S (2012) Validation of a clinical prediction scale for need for mechanical ventilation and inpatient mortality in acute exacerbation of chronic obstructive pulmonary diseases. Chest 142: 677.

7. Tabak Y, Sun X, Johannes R, Gupta V, Shorr AF (2009) Mortality and need for mechanical ventilation in acute exacerbations of chronic obstructive pulmonary disease. Arch Intern Med 169: 1595-1602. 